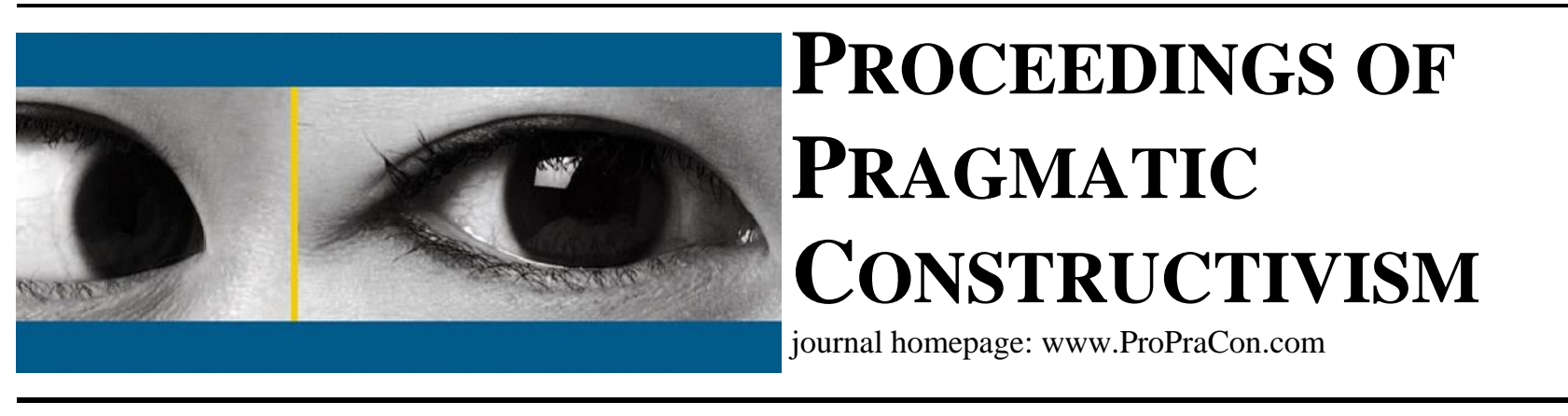

\title{
Accounting prototypes supporting product development: integrating different actors' viewpoints
}

\author{
Asta Rantamaa \\ Cost Management Center, Tampere University of Technology, \\ PO Box 541, FI-33101 Tampere, Finland; asta.rantamaa@talenom.fi \\ Teemu Laine \\ Cost Management Center, Tampere University of Technology, \\ PO Box 541, FI-33101 Tampere, Finland; teemu.j.laine@tut.fi \\ Tuomas Korhonen \\ Cost Management Center, Tampere University of Technology, \\ PO Box 541, FI-33101 Tampere, Finland; tuomas.korhonen@tut.fi
}

\begin{abstract}
This article introduces accounting prototypes in supporting managers in product development (PD), and inquires how accounting prototypes can support managers in PD activities. Accounting prototypes are jointly and iteratively created, preliminary tools, e.g., spreadsheets or information systems under development. Besides serving as control mechanisms, accounting prototypes also provide support for managers by integrating knowledge relevant to PD managers taking part in projects from different actors' viewpoints. However, previous literature offers insufficient understanding of how accounting prototypes could help PD managers. The paper is based on an interventionist case study of a machinery manufacturer's PD management. The focus of the case study was on the design and early use of accounting prototypes that would, right after PD execution, support production ramp-up, which was previously not much supported by accounting information. The paper contributes to the literature by showing an empirical example of supporting PD with accounting prototypes, and unveils the mechanisms through which the viewpoints of different business functions may be iteratively integrated in a calculation, thus enabling a more comprehensive view on the business impacts of a PD project. However, it was found out that the process of establishing and enhancing knowledge integration in the PD context is a longitudinal and challenging task also with the help of accounting prototypes.
\end{abstract}

Keywords: Product development; accounting prototypes; knowledge integration; pragmatic constructivism.

Acknowledgements: The research projects resulting in this paper have been funded by the Centre for Technology and Innovation in Finland (TEKES) and the Academy of Finland, which is here acknowledged. The authors wish also to thank the managers of the case company for the access to the fruitful dataset. 


\section{Introduction}

Despite monetary expressions represent the language of business (Avery, 1952), accounting information continuously fails in sufficiently supporting non-accountants, i.e. managers in different functions (Hall, 2010). Product development (PD) activities, in particular, are challenging to manage. In PD, managers often face uncertainty of knowledge about task outcomes (Jørgensen \& Messner, 2010), insufficient processes to integrate that uncertain knowledge with (Kraaijenbrink, 2012), and difficulties to make pragmatic use of the integrated knowledge. The existing information may not correspond to managers’ needs, thus hindering business performance (Wouters \& Verdaansdonk, 2002). Consequently, new accounting tools need to be developed along PD activities to support managers’ work.

This article introduces accounting prototypes in supporting managers in PD. Accounting prototypes are jointly and iteratively created, preliminary tools, e.g., spreadsheets or information systems under development. These accounting prototypes can be used as control mechanisms (Earl, 1978, 1982), but they also provide support for managers by integrating knowledge relevant to managers' workflow in and between decision making points (Wouters \& Roijmans, 2011), and, in essence, they provide a platform for enabling communication among different actor groups (Norreklit et al., 2010), that is PD managers (or parties involved in PD project in a broader sense). However, previous literature offers insufficient understanding of how accounting prototypes could help PD managers. The research question is: how can accounting prototypes support managers in PD activities?

To shed light on accounting prototypes supporting PD, an access to the actual interaction between accounting and engineering was needed. The authors of this paper conducted a qualitative, interventionist research project (Suomala \& Lyly-Yrjänäinen, 2011) that accesses a real-life setting in an engaged way (Van de Ven \& Johnson, 2006). The research project was carried out in a machinery manufacturing company in Finland, in 2012-2013, when the authors were involved with a large PD program in the company. The focus of the empirical study was on the design and early use of accounting prototypes that would support production ramp-up right after PD execution, which was previously not much supported by accounting information. Altogether, data were gathered from 30 meetings with 27 stakeholders. The data from the meetings were coded and analyzed with Atlas.ti software.

Understanding the requirements set for accounting practice (Ahrens \& Chapman, 2007), and justifying and defending its importance (see e.g., Norreklit et al., 2010) have recently been articulated as timely research topics. Accounting prototypes are supposed to provide new knowledge about facts, possibilities and values relevant to PD projects (see e.g., Cinquini et al. 2013), and could thus foster new forms of communication regarding PD management issues. The contribution and managerial implications of this article lies in adopting the idea of accounting development through certain prototypes to create new knowledge representations, new learning possibilities and new forms of knowledge transformation to respond to topical managerial challenges (Wouters \& Roijmans, 2011), in the PD management context. Based on our results, we propose that accounting prototypes represent a mechanisms through which the viewpoints of different business functions may be iteratively integrated in a calculation, thus enabling a more comprehensive view on the business impacts of a PD project. However, it was found out that the process of establishing and enhancing knowledge integration in the PD context is a longitudinal and challenging task also with the help of accounting prototypes.

The rest of the paper is structured as follows. The literature review synthesizes the requirements set for the content and use of accounting information in $\mathrm{PD}$, describes the existing understanding about accounting prototypes, and analyzes the accounting prototypes as means to respond to these requirements and enhance the accounting support in PD. The empirical section includes an overview of the empirical setting and data collection, findings regarding the accounting requirements in a large PD program studied, with a focus on the production ramp-up stage, and findings regarding the design and early use of the accounting prototypes designed by the interventionist researchers. The discussion section focuses on the support from accounting prototypes in the PD activities examined and presents implications to the PD and accounting literature. Conclusion section closes the paper.

\section{Literature Review}

\subsection{Requirements set for accounting information in product development}

In PD, there are contextual features that challenge the production and use of suitable accounting information for different managerial purposes. In this paper, we focus on: 1) the uncertainty of knowledge about task outcomes, which is due to the time-space distance between PD activities and the business impacts attained through them (Jørgensen \& Messner, 2010) and 2) the insufficient processes to integrate uncertain knowledge of different individuals and groups (Kraaijenbrink, 2012), which is due to the fact that PD activities require input from a number of different business 
functions to effectively anticipate and manage its business consequences. Additionally, accounting information provided for supporting PD activities should be suitable for pragmatic use of different individuals as PD project managers and PD project participants. The idea of accounting prototypes, as used in this paper is supposed to help the longitudinal improvement of accounting information from the viewpoint of its pragmatic use among managers.

First, regarding the uncertainty of the PD activities and the related accounting information, Nixon (1998) suggested that at a relatively early phase of a PD project, accounting is focused on relatively rough estimates on the business impacts and the qualitative information tend to dominate the decision-making. However, during the execution of the PD projects, the relative uncertainty decreases and the image of the business impacts sharpen, and there is more quantitative information available. In practice, Jørgensen and Messner (2010) reported that only part of the decisions in projects can be made based on accounting information, whereas complex phenomena under relatively high uncertainty require strategizing as the form of the decision making.

Davila and Wouters (2007) divide the units of analysis of accounting in PD into ex ante and ex post calculations, where the former refers to the business impact analyses, cost estimations (according to the cost targets) and cost budgeting of the PD activities, and the latter refers typically to the measurement of the PD projects (and more generally PD activities) according to the budgets and measuring the actual costs of the early prototypes and production batches of the new products. One challenge of accounting in supporting PD lies in the fact that although business impacts are being estimated beforehand, these estimations are only rarely revisited with actual information after project execution. The existence of multiple simultaneous objectives tend increase the challenge and uncertainty in the accounting figures related to the PD projects (Davila \& Wouters, 2007), and thus limits the availability of accounting information related to the decision-making situations (Jørgensen \& Messner, 2010). This is one possible reason for the extensive 'strategizing' in the PD project execution. The production ramp-up, as the empirical focus area of this paper, represent one example that is typically beyond the scope of the accounting information support for PD, because it extensively combines the estimates regarding the business impact estimates and the actual costs and profits of the first production batches.

Second, regarding the challenge of knowledge integration to support PD management, PD combines information and knowledge of a number of individuals and groups, and this knowledge integration clearly drives the performance of the PD activities. Clark and Fujimoto (1991) suggest that personnel becomes more and more specialized and is thus capable of producing new knowledge about such specialization. Such specialized knowledge is needed for performing as well as possible in the daily routines. The performance at the levels of the teams and the organization as a whole requires, however, knowledge integration. D’Adderio (2001) defines knowledge integration as the extent to which people communicate and cooperate with each other. In this paper, knowledge integration does not merely refer to the collection of desired accounting information to the accounting information systems for PD management purposes, but turning this information into action, for example by communicating the facts, possibilities and values among the parties involved (Norreklit et al. 2010) and by continuously ensuring that the PD performance measurement reflects the evolving requirements of the business environment (Korhonen 2014).

According to Ditillo (2012), management control systems represent important mechanisms in knowledge sharing. In knowledge intensive organizations (such as PD organizations in the context of this paper), the visibility of the rules and routines, the scalability if the estimations and decisions and the varying roles and responsibilities of individuals are desired characteristics from the viewpoint of the knowledge sharing. Obviously, it is the task of the top management to support and build concrete tools for enhancing communication. The organization should support the building of a shared values and identities and thus enabling knowledge sharing (Hansen, 1999). The viewpoint of the individuals remains easily at the individual level, if the organization does not provide a clear support for knowledge integration. Despite the focus on calculations, numbers and economic facts, Nørreklit et al. (2010) see accounting and control as a paradigm that is more closely related to social sciences than to natural sciences. Therefore, besides providing a possibility for assessing and analyzing economic facts, an accounting tool should primarily provide possibilities for individuals to better understand and communicate their values and valuations regarding the economic possibilities. Altogether, a lot of learning, knowledge sharing and trial and error is required to attain best possible tools for accounting and control.

Goffin et al. (2010) have studied organizational learning from prior PD projects. Among the central learning areas, they identify budgets and costs, organizational complexities, problem solving capabilities, product features, resources and schedules, and the application of the learning outcomes. A lot of expertise is required for really exploiting better the learning outcomes of the prior projects. A complex organization results in a fragmented knowledge about the PD activities and thus makes the PD management ineffective. Besides learning between the projects, there might be changes during the projects that require actions. Quite often the scope and the content are changed or the targets set for 
the projects in terms of product features, costs or time appear to be too ambitious (Goffin et al., 2010), and the accounting and control tools should serve in different purposes in responding to these challenges.

Altogether, due to the challenges in the PD context and the immaturity of the accounting and control practice, there is a clear need for accounting development. Due to the fact that PD activities integrate people and knowledge from different sources, also the accounting development should take this feature into accounting. In this paper, we examine one solution for responding to this challenge, i.e., accounting development through prototyping.

\subsection{The idea of accounting prototypes}

The idea of using prototypes also in accounting development can be found in two fragmented pieces of research. First, Earl $(1978,1982)$ studied prototype systems for accounting and control. He proposed that prototype thinking enables iterative development, as an alternative for mechanistic process-based development, and enables learning within the accounting and control system development (Earl 1982). Second, Wouters and Roijmans (2011) proposed only recently that prototypes could be beneficial in accounting development. A process with trial and error phases enables consideration of a number of alternatives, and integrating a number of different viewpoints along with the process. Experimenting in accounting development responds to the challenge of availability of accounting information as well as to the challenge of knowledge integration, the latter of which was especially highlighted by Wouters and Roijmans (2011). Despite the fact that both Earl $(1978,1982)$ and Wouters and Roijmans (2011) discuss product development as the natural context of prototyping, neither of the existing research efforts examine the accounting prototypes intended to support PD activities. This is perhaps due to the immaturity of accounting support for PD as discussed earlier.

In this paper, the accounting prototypes are defined as jointly and iteratively created, preliminary tools, e.g., spreadsheets or information systems under development. In this paper, the viewpoint is similar to the one that adopted by Wouters and Roijmans (2011). Instead of serving primarily as a control tool, accounting prototypes are intended to support the people under control of the centralized control systems. In this paper, we examine the accounting prototypes that aim at better supporting PD managers, PD project participants and the production ramp-up after the PD project execution. Besides integrative and cooperative design of the accounting prototypes, the development process intends to tools and reports that provide personal support for the parties involved.

Regarding the use of the accounting prototypes in supporting the PD activities, Table 1 summarizes the existing knowledge about the generic features, promised benefits and potential challenges of accounting prototypes (Earl, 1978; Wouters \& Roijmans (2011).

Table 1: Features, benefits and challenges of accounting prototypes.

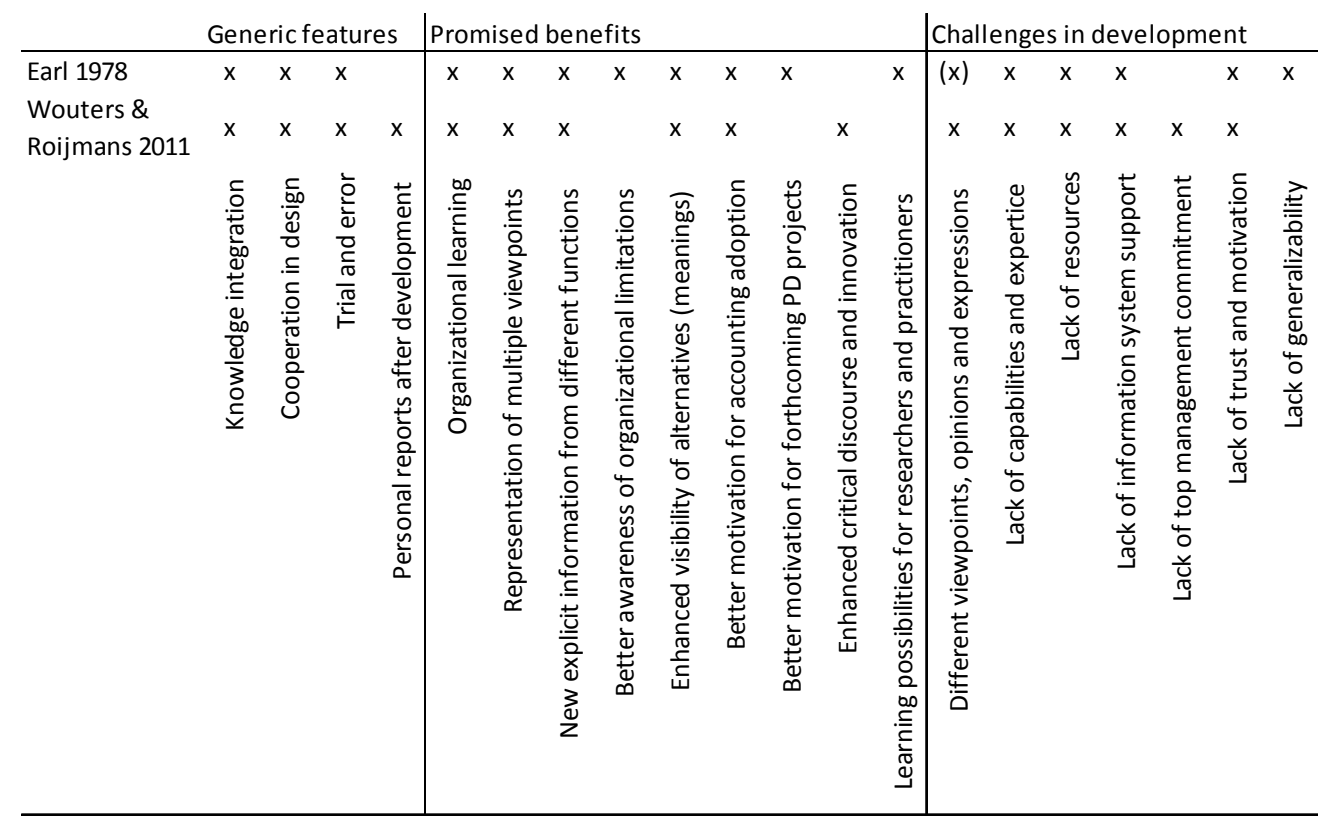

Wouters and Roijmans (2011) build on Carlile (2002) and suggest that experiment-based accounting development enhances knowledge integration especially regarding knowledge about different functions, different viewpoints, 
different alternatives and causes and effect more broadly. Shared responsibilities in accounting development are also supposed to motivation for adopting new accounting prototypes and to enhance critical discourse and innovation (Wouters \& Roijmans, 2011). Earl (1982) places an emphasis on the fact that a joint effort in developing accounting and control leads to higher responsibility for using the system and to higher motivation in forthcoming PD project execution. In general, accounting and control prototypes are supposed to provide a number of learning opportunities and also provide an extended understanding about current limitations in the given organization as a basis for further development.

On the other hand, however, there may be challenges in accounting development with prototypes. The integration of different viewpoints is a challenging task (Wouters \& Roijmans, 2011, see also Earl, 1978), especially in the PD context, where not much ex post information is available. Moreover, there might be a lack of resources, capabilities and top management support available for developing those accounting prototypes (Earl, 1978, 1982; Wouters \& Roijmans (2011). Earl (1978) pointed out also, quite reasonably, that if the accounting prototypes are designed only for a certain decision-making situation, the lack of generalizability limits the use and value of the prototypes.

\subsection{Using accounting prototypes to enrich accounting support for product development}

Accounting development, similarly to any development effort, features many actors that are not all human beings (Briers \& Chua 2001, see also Nørreklit et al., (2010). Among those non-human actors, there might be beneficial tools to enhance knowledge integration and communication. In the PD context, boundary objects are defined as means to define and communicate the viewpoint of a specific actor (group) (Bechky, 2003; Briers \& Chua 2001; Carlile, 2002). In the PD context, such boundary objects might be of value both for PD project management and in enhancing the accounting support for those projects. Accounting prototypes represent boundary objects that may be beneficial in accounting development for the different purposes of PD managers and PD project participants.

Mouritsen et al. (2009) suggest that the accounting information is supposed to offer a broader view to innovations by providing information on the organizational challenges. Calculations as 'short translations' provide such a view regarding a limited number of viewpoints, whereas 'long translations' provide more extensive view on the business phenomena. The potential for calculations lies in their ability to enhance communication between the innovation (or PD) activities and the overall limitations and timely business phenomena in the organizations. Accounting prototypes may provide a basis for establishing and enhancing such communication within an organization. This is in line with the idea of D’Adderio (2001) and Nørreklit et al. (2010) that calculations may provide social structures and means of communication among different actors. Through accounting prototypes, there is the possibility to further enhance the knowledge integration and communication to the benefit of different actors and the organization as a whole (Earl 1978, 1982; Wouters \& Roijmans 2011).

\section{Empirical findings}

\subsection{Overview of the case and the data collection}

The paper is based on a qualitative, interventionist research project (Suomala \& Lyly-Yrjänäinen, 2011; Suomala et al., 2014). The research project was carried out in a machinery manufacturing company in Finland, in 2012-2013, that produces production machinery and related services to its customers. The company is highly innovative and has significant PD activities. The company has implemented management models for PD project selection and steering, there are already tools and resources for estimating the business impacts (volumes, prices, costs, etc.) of the products under development. However, production ramp-up at the very end of the PD projects was identified to require extra attention.

The focus of the empirical study was on the design and early use of accounting prototypes that would support production ramp-up right after PD execution, which was previously not much supported by accounting information. In the ramp-up phase, the ex ante business impact analyses become comparable with the early calculations of actual costs and profits. The role of the ramp-up phase management is, therefore, twofold. First, in the ramp-up phase, the actuals can be compared with targets/estimates, and the management can possibly steer the project to ensure meeting the targets set. Second, the ramp-up phase determines, how well and how fast the target levels will be met (e.g., in terms of the benefits of the batch production) and how much extra costs do the ramp-up phase cause before the target profits will be met. The extra costs may be due to a lack of demand of the new product or to problems in the production system of the 
company. The role of the researchers were to collect data from different sources to build a model of the business impacts of the PD project and provide alternative scenarios for the production ramp-up with different cost implications.

The data comprises participatory observations, meetings, interviews, email and memos of phone calls. Moreover, there was an extensive access to the company's documentation regarding the PD program and the ramp-up plans. This paper is based on 30 interviews and meetings with 27 individuals (9/2012-5/2013). Moreover, one researcher worked also one week in the production line of the case company. The people represented in the interviews, meetings and informal occasions are summarized in Table 2.

In some occasions, there were many people present across the business functions. Production management/personnel, financial management and product development management/personnel were most often met. The researchers were in a close cooperation with one person, who was responsible for cost estimation of the new products, which enhanced the access of the researchers to the meetings. However, the design and early use of the rampup scenarios as accounting prototypes were a task given to one of the researchers. This was in response to the lack of resources for accounting development in the company and also in response to the use of an external, 'objective' actor as a knowledge integrator. These aspects seem to tackle some of the challenges connected to the accounting development through prototyping (Earl, 1978; Wouters \& Roijmans, 2011).

Table 2: People involved in the interviews and meetings.

Roles present in the meetings
PD program manager
PD personnel
Research personnel
Purchasing
Production
Sales
After sales
Business controller / finance
Another division
Total

According to Jönsson and Lukka (2007), interventionist case study requires an extensive and chronological documentation of the research process and empirical material. The empirical data underlying this paper was documented on a daily basis and coded with the help of Atlas.ti software to enable qualitative analyses iteratively and after the research process. From the viewpoint of this paper, the codes used in the Atlas.ti analyses include the role of an actor (business function, such as production), an information need of an actor group (business function, such as production). Moreover, the findings were coded separately as the benefits/enablers and challenges of knowledge integration.

\subsection{Requirements set for accounting information in the PD program and ramp-up}

The business impact analysis of a PD project, conducted in the company, includes estimates on the volumes, prices, costs and after sales profits of the product under development. The business impact analysis represents a basis for choosing and steering of a PD project. In the studied PD program, the business impact analysis was conducted for a number of products, altogether constituting the business impacts and target of the program as a whole. The accounting prototypes designed for the ramp-up management intended to support the ramp-up phases of individual products, and the accounting prototypes were supposed to be developed along with the program execution. The findings of this paper are related to the first ramp-up within the wider PD program.

Although the business impact analyses included estimates of the volumes of the new products after the ramp-up, not much attention were paid to the actual timing of the ramp-up phase. The interviews and meetings among sales, production and purchasing departments revealed that the optimal ramp-up schedule differs dramatically from a function to another. For the sales people, it was important to sell the previous model as long as possible and only gradually start selling the new model, to prevent a situation where the customers should wait the delivery of the product longer due to the ramp-up phase. For the production management, a fast and strict process for ramp-up and ramp-down was desired, 
thus enabling a fast learning curve in the assembly of the new product and a straightforwardly meeting the production cost targets set for the new product. For the purchasing representatives, a gradual, yet relatively fast shift to the new product would enable an easily manageable process for materials management for the purposes of the old and new product models.

The different requirements regarding the ramp-up management with significant implications to profitability revealed the fact that the ramp-up was not sufficiently defined in the company to enable an effective management of it right after the PD project execution. The PD program manager showed the definition of the ramp-up according to the documentation of the company:

\section{"[From the PD viewpoint] production ramp-up means the shift of the product [responsibility] from PD to production. During the ramp-up, old models may still be produced, before a ramp-down process takes place”.}

However, as discussed with different functions, the definition of the ramp-up required more details and accounting information was required to better understand the profitability impacts of different alternatives. Part of the uncertainty related to the ramp-up management seemed to be due to a lack of knowledge integration between the PD personnel and production representatives, as well as between purchasing, production and sales \& marketing functions. Therefore, as a starting point for the accounting development, and more particularly as a starting point for designing the accounting prototypes, there was a need for an integrative view on the ramp-up.

As a result, based on the interviews among different people in the case company, the following characteristics were connected with the ramp-up phase:

- production ramp-up may be defined as meeting specific targets set for the new product (e.g., the production cost target or production volume of the new product)

- meeting such targets requires certain sales volumes (sales management) and additional ramp-up management outside the assembly line (purchasing and supplier network management)

- meeting such targets seem to require more time than previously estimated in the business impact analyses (e.g., in terms of the learning curves in the assembly line)

- ramp-down of an old product model should be included in the overall process of the ramp-up, if it is understood as a means to manage the business impacts of the new product.

Altogether, the discussion of the aforementioned ramp-up characteristics offered one form of knowledge integration desired in the case company. At the same time they revealed the need for different pieces of information required in building the desired accounting prototypes. Those prototypes were supposed to serve as boundary objects in further communication regarding the ramp-up phase, and potentially in more effective ramp-up management.

\subsection{Design and early use of the accounting prototypes}

To simplify the development and early use of the accounting prototypes in the company, two separate phases may be identified. First, an early version of the business impacts of the ramp-up was designed to show the overall profitability impacts of the ramp-up management to provide a knowledge presentation (Wouters \& Roijmans 2011), or the first long translation (Mouritsen et al. 2009) about profitability impacts of the ramp-up phase (year 2012). Second, the second prototype was built based on an enhanced understanding about the ramp-up definition and the feedback attained from the previous prototype, as the second long-translation about the key business phenomena in the ramp-up phase (year 2013).

The first accounting prototype combined the viewpoints of the different functions and provided a view on the best, realistic and worst case of the production ramp-up. An illustrative Figure 1 conveys the best case scenario, where the ramp-up results in a gradual increase in the sales and production volumes. Both the ramp-up and ramp-down are managed so that the production and materials supply succeeds in meeting the market demand. In the realistic case, there was a temporal decrease in production volumes, whereas the worst case included major problems in the production and the material supply as well as in the market demand of the new product. 
Figure 1: First accounting prototype about the profitability impacts of the ramp-up.

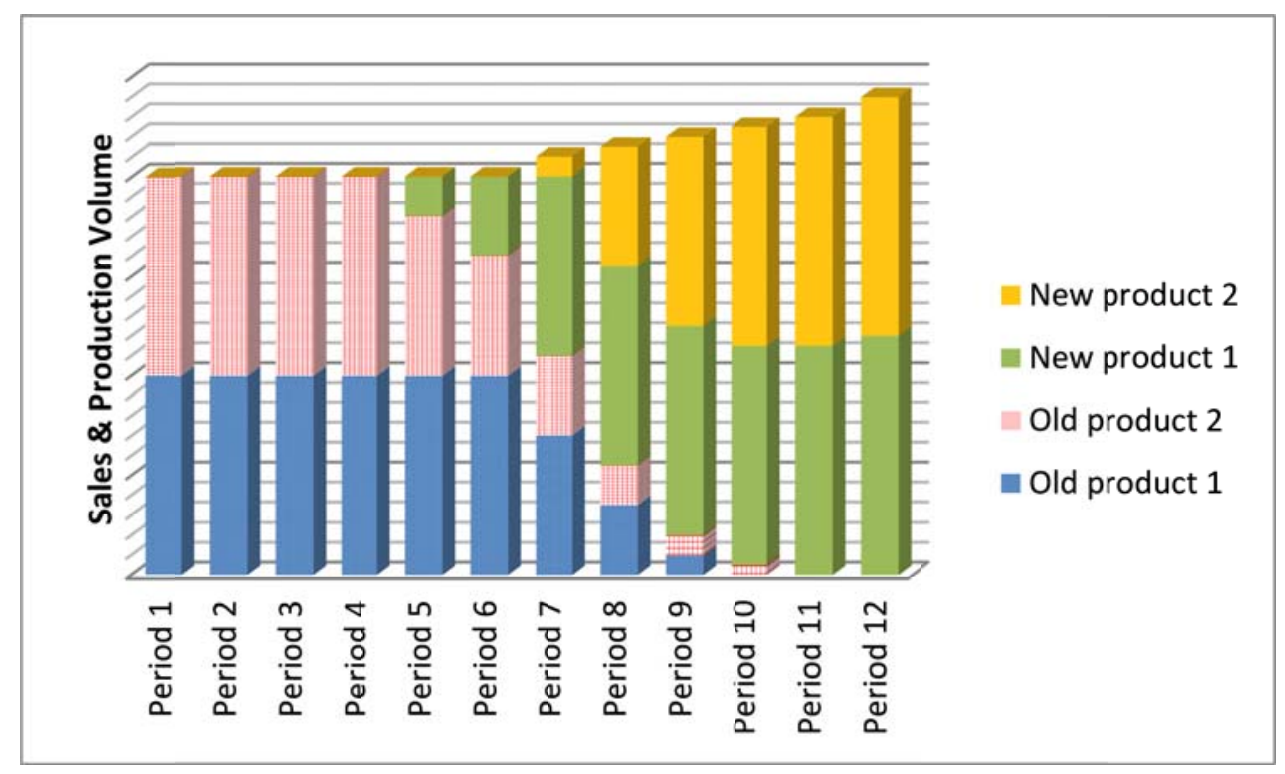

The first accounting prototype enabled discussions regarding the importance of the ramp-up management, as the differences in the profitability impacts between different scenarios were significant. However, this prototype did not yet include many possibilities to further analyze the profitability impacts and draw managerial implications for different PD project participants. As a result, the second prototype was supposed to focus on certain details of the ramp-up phase and provide deeper understanding about the profitability impacts.

Based on the previous discussions, the focus of the second accounting prototype was now placed on the following aspects in the ramp-up scenarios: 1) In the PD project, there were discussions about the impact of meeting the schedule set for the design of the product, and the ramp-up tool thus included the possibility to postpone the ramp-up in order to analyze those impacts. 2) Another aspect, already discussed with different functions, was the rate at which the new product replaces the old one in the production. This kind of analysis was also enabled in the ramp-up tool. 3) One of the targets set for the new product was an enhanced modular structure, the profitability effects of which were estimated based on the possibility for capacity increase and based on the lower complexity of the product structure, thus resulting lower production management costs. 4) Learning curve in the assembly line was estimated to better understand the need for extra capacity in the production during the ramp-up phase and the extra costs caused by different ramp-up scenarios. This kind of information was previously available in the production department, but was now for the first time used between PD and production representatives.

As a result, the researchers presented a refined ramp-up tool as the second accounting prototype (Wouters \& Roijmans, 2011) to the company representatives. The central report of the tool is presented in an illustrative Figure 2. By using the tool, different scenarios can be built regarding the timing and content of the ramp-up, thus resulting in different profitability impact estimates.

The use of the second accounting prototype led to the reconsiderations of the ramp-up execution in the case company. Earlier, the plan was to execute the ramp-up much faster, but the ramp-up was during the process decided to be divided more clearly into different product ramp-ups within the PD program. In other words, more time and attention was given to the ramp-up management of single products.

One may, of course, question, whether the accounting prototypes really changed the decision-making in the company. In fact, the decisions were not made clearly based on the built scenarios with the help of the accounting prototype, but the accounting development as a part of the PD program execution drew the attention of the parties involved to the central profitability impacts related to the ramp-up phase.

The results of this study suggest that there can be considerable disagreement among PD stakeholders regarding central PD issues, such as the definition and the content of the ramp-up right after the PD project. However, accounting information can help negotiations between the project participants, and eventually provide a consensus of a topic. Then early accounting prototypes had the role of visualizing different stakeholders' contradictory perceptions of that 
procedure, and lead to drawing attention to bottlenecks. Further, developing accounting prototypes together with employees could make the calculations more reliable and reduce the level of uncertainty in PD process.

Figure 2: Refined accounting prototype about the profitability impacts of the ramp-up.

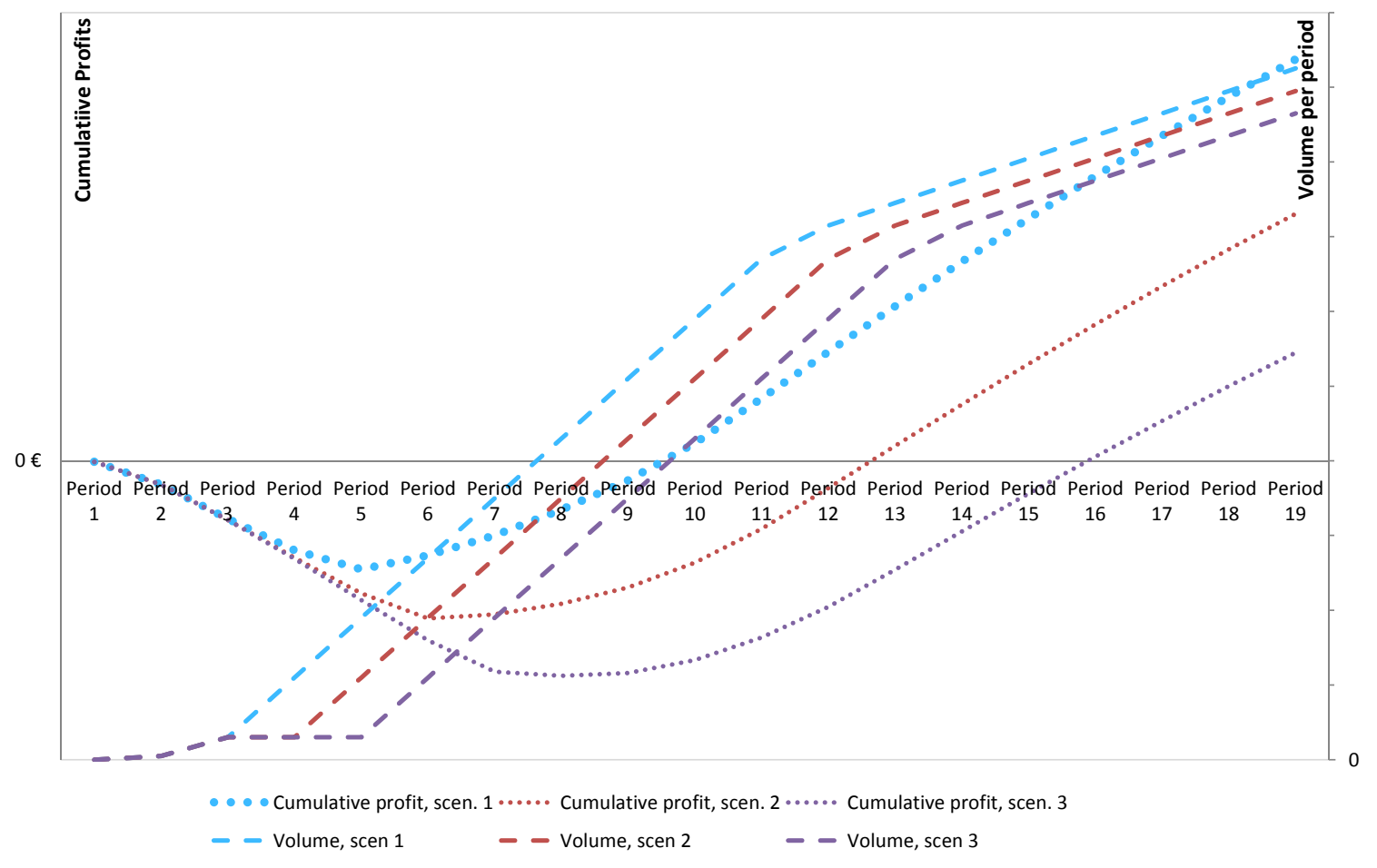

\section{Discussion}

Prototyping in accounting development for supporting PD project management was an uncharted research territory. Both Wouters and Roijmans (2011) and Earl (1978, 1982) discuss developing accounting through prototypes at a relatively general level and in the context outside PD activities. In Table 3, the relationship between this paper and the earlier studies on accounting development through prototypes is put together.

Table 3: The relationship between this paper and earlier studies on accounting development through prototypes.

\begin{tabular}{|c|c|c|c|c|}
\hline Study & Unit of analysis & Context & Method & Key finding \\
\hline Earl 1978 & $\begin{array}{l}\text { Accounting information } \\
\text { system }\end{array}$ & $\begin{array}{l}\text { Information systems, } \\
\text { engineering and learning } \\
\text { organizations literature } \\
\text { used in purchasing }\end{array}$ & Case study & $\begin{array}{l}\text { Prototyping begins with } \\
\text { early drafts, the latest } \\
\text { version is stored in the } \\
\text { system }\end{array}$ \\
\hline Wouters and Roijmans 2011 & $\begin{array}{l}\text { Performance } \\
\text { measurement system } \\
\text { (PMS), including support } \\
\text { for particular managers }\end{array}$ & $\begin{array}{l}\text { Accounting and new } \\
\text { product development } \\
\text { literature used in a } \\
\text { logistics environment }\end{array}$ & Action research & $\begin{array}{l}\text { Prototypes are drafts t } \\
\text { help in identifying right } \\
\text { questions and respondi } \\
\text { to them }\end{array}$ \\
\hline The present study & $\begin{array}{l}\text { Actor approach for } \\
\text { accounting information } \\
\text { system: a set of } \\
\text { calculations supporting } \\
\text { PD \& ramp-up } \\
\text { execution from the } \\
\text { viewpoint of multiple } \\
\text { actors }\end{array}$ & $\begin{array}{l}\text { accounting, information } \\
\text { processes and new } \\
\text { product development } \\
\text { literature used to enrich } \\
\text { accounting for PD }\end{array}$ & $\begin{array}{l}\text { Action research / } \\
\text { Interventionist research }\end{array}$ & $\begin{array}{l}\text { Prototypes are } \\
\text { developed based on } \\
\text { challenges and } \\
\text { requirements and } \\
\text { present economic } \\
\text { impacts of given } \\
\text { phenomena }\end{array}$ \\
\hline
\end{tabular}


The present study considers the accounting prototypes as calculations that are intended to support individual actors, actor groups and the organization as a whole in their managerial work. This viewpoint is adapted from Wouters and Roijmans (2011) to the PD management context, and enriched with the considerations labeled as the actor approach (Norreklit et al. 2010, Cinquini et al. 2013). Similarly to the study by Wouters and Roijmans (2011), accounting prototypes seemed to provide new means for knowledge representation and integration and thus providing new learning opportunities. By building on the actor approach, accounting prototypes seem to represent a means to foster informal communication among different actors with a help of an accounting device in the making.

It is noteworthy that due to the significant uncertainty related to the PD activities and the immaturity of the accounting support in the PD context, a longitudinal accounting development is required to redirect decision-making with the help of new accounting information. One of the key implications possibly provided by the accounting prototypes in PD is the possibility to enhance learning within and across the PD projects (the challenge identified by Goffin et al. 2010).

Accounting represents the language of business (Avery, 1952), and is thus a natural starting point for knowledge integration in the PD context, the potential of which is not (at all) realized (see e.g., Davila \& Wouters, 2007). In line with the idea of Mouritsen et al. (2009), we found out that the accounting calculations fostered new types of discussion among the PD project participants that are not necessarily used to discuss the profitability impacts of the new products, but more readily the technical aspects or other sources of innovation in the new products. According to Kraaijenbrink (2012), PD project success is driven by the success of knowledge integration in it. Using accounting prototypes in establishing new ways of knowledge integration and enhancing the existing ones is thus a clear way forward in enable the success of the PD projects in the companies.

\section{Conclusion}

Prototyping is a mechanism that has shown its ability to provide a basis for knowledge integration, communication and trial and error, thus enhancing PD performance. Establishing and enhancing the support of accounting for PD activities require analogous characteristics, which constitutes a natural starting point for accounting development through prototypes. Although the idea of accounting prototypes has been presented already in the accounting literature, this paper takes the discussion back to the PD context. The paper contributes to the literature by showing an empirical example of supporting PD with accounting prototypes.

First, the paper unveils the mechanisms through which the viewpoints of different actors representing different business functions may be iteratively integrated in a calculation, thus enabling a more comprehensive view on the business impacts of a PD project. However, the paper was empirically limited to a production ramp-up phase of a PD project and, therefore, further research is required to shed light on the accounting development through prototypes in different PD context, regarding different phases of PD project execution.

Second, it was found out that the process of establishing and enhancing knowledge integration in the PD context is a longitudinal and challenging task also with the help of accounting prototypes. The learning possibilities between (and within) PD projects are not taken full advantage of in the PD organizations. Accounting prototypes provide a (boundary) object for enhancing learning regarding business impacts of the PD projects. However, more longitudinal setting would be required to shed light on the actual mechanisms through which the accounting prototypes turn into established rules and routines in organizations, and as a result realize those learning possibilities.

Finally, the interventionist case study has its limitations due to the qualitative nature of the collected data and relatively subjective process of data interpretation and analysis. On the other hand, however, the role of the empirical data in this paper is primarily to illustrate the possibility to develop accounting support for PD through prototyping. The unique access of the researchers to the data set provides an advantage for this setting to reveal the real-life complexities and challenges underlying accounting development in the PD context. However, more extensive data would be required to strengthen the transferability of the results regarding the scope and the content of the accounting prototypes. 


\section{References}

Ahrens, T., Chapman, C. 2007. Management accounting as practice. Accounting, Organizations and Society, 32(1/2), $1-27$.

Avery, H. G. 1952. Accounting as a Language. The Accounting Review, 28(1), 83-87.

Bechky, B. A. 2003. Sharing meaning across occupational communities: the transformation of understanding on a production floor. Organization science, 14(3), 312-330.

Briers, M., Chua, W. F. 2001. The role of actor-networks and boundary objects in management accounting change: a field study of an implementation of activity-based costing. Accounting, Organizations and Society, 26, 237-269.

Carlile, P. R. 2002. A pragmatic view of the knowledge and boundaries: boundary objects in new product development. Organization science, 13(4), 442-455.

Cinquini, L., Mitchell, F., Nørreklit, H., \& Tenucci, A. 2013. Methodologies for managing performance measurement. In F. Mitchell, H. Nørreklit \& M. Jakobsen (Eds.), The Routledge companion to cost management (pp. 360380) Routledge, Abingdon, Oxon, New York.

Clark, K. B., Fujimoto, T. 1991. Product development performance: Strategy, Organization, and management in the world auto industry. Boston, Harvard business school press.

D’Adderio, L. 2001. Crafting the virtual prototype: how firms integrate knowledge and capabilities across organizational boundaries. Research Policy, 30, 1409-1424.

Davila, T., Wouters, M., 2007. Management accounting in the manufacturing sector: managing costs at the design and production stages, in: Chapman, C.S., Hopwood A.G., Shields, M. (Eds.), Handbook of Management Accounting Research. Elsevier, Amsterdam, The Netherlands, 2, 831-858.

Ditillo, A. 2012. Designing management control systems to foster knowledge transfer in knowledge-intensive firms: a network-based approach. European accounting review, 21(3), 425-450.

Earl, M. J. 1978. Prototype systems for accounting, information and control. Accounting, Organizations and Society, 3(2), 161-170.

Earl, M. J. 1982. Prototype systems for accounting, information and control. Data base, 23(2-3), 39-46.

Goffin, K., Koners, U., Baxter, D., van der Hoven, C. 2010. Managing lessons learned and tacit knowledge in new product development. Industrial research institute, 10, 39-51.

Hall, M. 2010. Accounting information and managerial work. Accounting, Organizations and Society, 35, $301-315$.

Hansen, M. T. 1999. The search-transfer problem: the role of weak ties in sharing knowledge across organizational subunits. Administrative science quarterly, 44, 82-111.

Jönsson, S., Lukka, K. 2007. There and back again: Doing interventionist research in management accounting, in: Chapman, C.S., Hopwood A.G., Shields, M. (Eds.), Handbook of Management Accounting Research. Elsevier, Amsterdam, The Netherlands, 1, 373-392.

Jørgensen, B., Messner, M. 2010. Accounting and strategizing: A case study from new product development. Accounting, Organizations and Society, 35(2), 184-204.

Korhonen, T. 2014. Performance Measurement Dynamism in Product Development. Doctoral Dissertation. Tampere University of Technology, Tampere, 161p.

Kraaijenbrink, J. 2012. Integrating knowledge and knowledge processes: a critical incident study of product development projects. The Journal of Product Innovation Management, 29(6), 1082-1096.

Nixon, B. 1998. Research and development performance measurement: a case study. Management Accounting Research, 9, 329-355.

Nørreklit, H., Nørreklit, L., Mitchell, F. 2010. Towards a paradigmatic foundation for accounting practice. Accounting, Auditing \& Accountability Journal, 23, 733-758.

Suomala, P., Lyly-Yrjänäinen, J. 2011. Management Accounting Research in Practice: Lessons Learned from an Interventionist Approach. Routledge, New York.

Suomala, P., Lyly-Yrjänäinen, J., Lukka, K. 2014. Battlefield around interventions: A reflective analysis of conducting interventionist research in management accounting. Management Accounting Research, 25.

Van de Ven, A., Johnson, P. E. 2006. Knowledge for theory and practice. Academy of Management Review, 31(4), 802-821.

Wouters, M., Verdaasdonk, P. 2002. Supporting management decisions with ex ante accounting information, European Management Journal, 20(1), 82-94.

Wouters, M., Roijmans, D. 2011. Using prototypes to induce experimentation and knowledge integration in the development of enabling accounting information. Contemporary Accounting Research, 28(2), 708-736. 